\title{
Screening Mammography and Pap Tests Among Older American Women 1996-2000: Results from the Health and Retirement Study (HRS) and Asset and Health Dynamics Among the Oldest Old (AHEAD)
}

Truls Østbye, $M D, M P H, M B A, P b D^{4}$ Gary N. Greenberg, $M D, M P H^{2}$ Donald H. Taylor, Jr, MPA, PbD ${ }^{1}$ Ann Marie M. Lee, MPH, CHES ${ }^{2}$

'Department of Community and Family Medicine \& Center for Health Policy, Law and Management, Duke University Medical Center, Chapel Hill, NC

${ }^{2}$ Department of Community and Family Medicine, Duke University Medical Center, Chapel Hill, NC

\begin{abstract}
BACKGROUND We wanted to determine the frequency of self-reported receipt of screening mammography and Papanicolaou (Pap) tests in older women and investigate important predictors of utilization, based on 2 national longitudinal surveys.

METHODS This cohort study includes participants from 4 waves (1994-2000) of the Health and Retirement Study (HRS) - 5,942 women aged 50 to 61 years, and 4 waves (1993-2000) of the Asset and Health Dynamics Among the Oldest Old (AHEAD) survey-4,543 women aged 70 years and older. The self-reported receipt of screening mammograms and Pap smears in the most recent 2 years were reported in 1996 and 2000 for HRS, with predictors of receipt measured in 1994 and 1998. In AHEAD, the self-reported receipt of screening mammograms and Pap smears in the most recent 2 years were reported in 1995 and 2000, with predictors of receipt measured in 1993 and 1998.
\end{abstract}

RESULTS Receipt of mammography is stable at $70 \%$ to $80 \%$ among women aged 50 to 64 years, then declines to around 40\% among those aged 85 to 90 years. For Pap tests there is a decline from 75\% among women aged 50 to 54 years to $25 \%$ in those aged 85 to 90 years. For both mammography and Pap tests, the rates increased in all groups from 1995/1996 to 2000. Higher education, being married, higher income, not smoking, and vigorous exercise were consistently associated with higher rates of receipt.

CONCLUSIONS Although the use of mammography and Pap tests for screening declines into old age, use has been increasing recently. The large and increasing number of tests performed might not be justified given the lack of evidence of effect in older age-groups.

Ann Fam Med 2003;1:209-217. DOI: 10.1370/afm.54.

\section{INTRODUCTION}

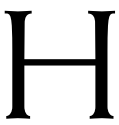
ealth maintenance care for young adults is focused on identification and reduction of long-term health risks, whereas care for elderly patients is generally focused on case finding. Early discovery of treatable, asymptomatic cancers is an important motive for patients and clinicians, but an important question persists: Is it reasonable to screen for common cancers in the elderly? 
The exponential age-related increase in incidence of some cancer types argues in favor of increased screening. Furthermore, case fatality rates also increase with age. ${ }^{1}$ There is also evidence that increasing age is associated with an increasing "sojourn time," which begins when cancer might first be detected by screening and ends when cancer is detected through the appearance of symptoms. Given a certain screening interval, increased sojourn time allows a larger proportion of cancers to be detected in a preclinical stage.

Life expectancy obviously decreases with age, however, and the competing risk of dying from other diseases increases rapidly, reducing the number of years that can be saved through screening. There is also a selection problem: the healthiest elderly, with lower risk of disease, are more likely to be screened. For example, in a Dutch breast cancer-screening study, ${ }^{2}$ those who were screened lived 2 years longer than those who were not, even when the effects of screening on breast cancer mortality were statistically excluded. Thus, the apparent benefit of screening is falsely increased by patient self-selection.

Furthermore, there are no rigorous studies showing that screening of the very old provides clear benefits. Most studies have excluded the very old. In the Swedish Two County Trial of mammography, ${ }^{3}$ screening that began in the oldest age-group (ages 70 to 74 years) was abandoned because of poor attendance.

\section{Clinical Guidelines}

Reflecting these opposing considerations and the lack of evidence, it is not surprising that cancer-screening practice guidelines are ambiguous and inconsistent for elderly women.

\section{Breast Cancer}

For women aged 50 to 69 years, guidelines are consistent with regard to annual or biannual mammograms. ${ }^{4-8}$ After the age of 70 years, most recommendations cite inconclusive evidence for the need for mammograms but support them so long as the woman is healthy enough to endure the treatment regimen for any detected cancer. The American Cancer Society differs slightly, ${ }^{6}$ providing no specific age for cessation and stating that comorbidity is the only qualifying factor for exclusion from screening. The Health Plan Employer Data and Information Set (HEDIS) parameters are report cards for clinical practice that affect clinical reimbursement and group practice certification; the HEDIS breast cancer-screening rate includes women aged 52 to 69 years. ${ }^{9}$ Finally, Healtby People $2010^{10}$ has set as a target that $70 \%$ of all women aged 40 years or older should have received a mammogram within the preceding 2 years.

\section{Cervical Cancer}

Most recommendations relating to Papanicolaou (Pap) smears suggest that they should be done after a woman has sexual intercourse or by age 18 years if her sexual activity status is unknown. ${ }^{5-8}$ Most recommend screening at a minimum of 3-year intervals even after a series of 3 Pap test results have been normal. The American Cancer Society ${ }^{6}$ suggests that women aged 70 years of age or older who have had 3 or more normal Pap test results in a row and no abnormal test results in the last 10 years may choose to stop having cervical cancer screening.

The HEDIS cervical cancer screening measure is based on women aged 21 to 64 years, ${ }^{9}$ but Healtby People $2010^{10}$ has set as targets that by $2010,97 \%$ of all women aged 18 years or older should have ever received a Pap test, and $90 \%$ of these women should have received it within the preceding 3 years.

Given the uncertain benefits, combined with the substantial economic and psychological costs associated with large-scale screening, it is of interest to document whether screening for common cancers among women persists into old age and to investigate factors associated with such screening practices.

The objective of these analyses was to document the provision and receipt of mammography and Pap tests with respect to age using 2 large national studies of middle-aged and older Americans. We investigated how self-reported utilization frequencies vary by age, and whether there have been any recent (from 1996 to 2000) changes in these frequencies. The importance of plausible (demographic, socioeconomic, health, and health care) predictors of utilization are investigated in multivariate analyses.

\section{METHODS}

\section{Data}

The Health and Retirement Study (HRS), ${ }^{11}$ a national panel study, contains information about health behaviors, disease and disability, and medical care usage. The baseline survey was conducted in 1992 for the 1931-1941 birth cohort of women (and their spouses, regardless of age) $(n=12,652)$. Questions relating to receipt of clinical preventive services, including certain cancer-screening tests, were included for all participants in wave 3 (1996) and wave 5 (2000). In our analyses, women who responded to these questions in at least 1 wave were included $(n=5,942)$.

The Asset and Health Dynamics Among the Oldest Old (AHEAD) is a companion study including an older age-group. ${ }^{12}$ The initial sample (wave 1 in 1993) included respondents aged 70 years and older (and their 
spouses, regardless of age) $(\mathrm{n}=7,447)$. Persons older than 80 years were oversampled to allow for more precise estimates in this group. Follow-up interviews were conducted in 1995, 1998, and 2000. The questions pertaining to mammography screening and Pap tests were asked of all respondents in wave 2 (1995) and in wave 4 (2000), and women who answered these questions at least once are included in our analyses $(n=4,543)$. African Americans (blacks) were oversampled (100\%) in both surveys.

\section{Dependent Variables}

The questions (both from the preventive procedures section of the questionnaires) were as follows: (for mammogram) "Did you have a mammogram or x-ray of the breast, to search for cancer in the last two years?" and (for Papanicolaou test) "In the last two years, have you had any of the following medical tests or procedures: a Pap smear?"

\section{Explanatory Variables}

Cancer screening was reported in 1996 and 2000, with the corresponding explanatory variables measured in 1994 and 1998, respectively, for HRS. In AHEAD, reports on cancer screening were collected in 1995 and 2000, with the corresponding explanatory variables measured in 1993 and 1998, respectively. Age was grouped in 5-year intervals. Other explanatory variables included racial group (black, white), education (at least some college education, completed high school or less), place of birth (United States, abroad), marital status (married, unmarried), smoking (current smokers, nonsmokers), exercise (vigorous, lower levels of physical activity) and self-reported health (fair or poor, excellent, very good or good). Subjective life expectation was coded as high, medium, and low (footnote, Table 1). Household income was categorized into 4 groups (footnote, Table 1 ). In HRS respondents who had no health insurance were compared with those who had any type of health insurance $_{\text {; }}$ in AHEAD, where nearly all participants were insured by Medicare, those who had additional, private insurance were compared with those who had none. Participants who had been hospitalized in the last year were compared with those who had not. Number of outpatient physician visits was categorized as 0 to 2,3 to 5,6 or more.

\section{Analyses}

The weighted proportions (taking into consideration oversampling of blacks and residents in certain states) of respondents who reported having received the screening test since the previous wave were calculated by year (wave: 1995 [AHEAD] and 1996 [HRS], and
2000) and age-group. For consistency with the multivariate analyses, the sampling weights were from the previous wave (see below).

The weighted relationships between the explanatory and screening variables were tabulated for respondents who completed the screening question in 1995/1996 or 2000 , or both. Because the outcome question referred to receipt of the screening test in the interval between the current and the previous wave ("In the last two years ..." or "... since we spoke to you last."), the values of the explanatory variables from the wave preceding the value of the outcome variable were selected (ie, explanatory variables $1994 \rightarrow$ outcome 1995/1996; explanatory variables $1998 \rightarrow$ outcome 2000.) Using multivariate logistic regression, models were first developed separately for outcomes reported in the $1995 / 1996$ wave and for the outcomes reported in the 2000 wave (not shown). Subsequently, observations for each respondent were stacked (each respondent provided 2 outcome values and 2 sets of explanatory values). In the latter models, because the observations for the same person in different waves are not independent of each other, clustering of observations at the individual level was adjusted by using Huber-White corrected standard errors. ${ }^{13,14}$ Although similar explanatory variables were used, models were estimated separately for AHEAD and HRS. In addition to simple models including only wave and demographic variables (age and racial group) (not shown), more extensive models were also developed including explanatory variables from the socioeconomic, health, and health care domains.

STATA (version 6.0) was used for the statistical analyses.

This study proposal was approved by the Duke University Medical Center Institutional Review Board.

\section{RESULTS}

For both mammography and Pap tests, the rates increased among all age-groups from 1995/1996 to 2000. Receipt of mammography (Figure 1 ) by age was relatively stable at $70 \%$ to $80 \%$ until approximately age 70 years, at which time it declined to about $40 \%$ among those aged 85 to 90 years. For Pap tests (Figure 2), there was a decline by age from $75 \%$ at age 50 to 54 years to $25 \%$ at age 85 to 90 years.

Table 1 shows that, in bivariate analyses of HRS data, there were few differences by racial group or country of birth for receipt of either of the screening tests. Higher education levels, being married, and higher income were all positively related to receipt of both screening tests. Nonsmokers were more likely to have undergone screening, as were those who perceived their health as excellent, very good, or good. 
Table 1. Receipt of Preventive Services by Survey Wave in Selected Subgroups (Weighted Percentages)

\begin{tabular}{|c|c|c|c|c|c|c|c|c|}
\hline \multirow[b]{3}{*}{ Variables } & \multicolumn{4}{|c|}{ HRS } & \multicolumn{4}{|c|}{ AHEAD } \\
\hline & \multicolumn{2}{|c|}{ Pap Test } & \multicolumn{2}{|c|}{ Mammogram } & \multicolumn{2}{|c|}{ Pap Test } & \multicolumn{2}{|c|}{ Mammogram } \\
\hline & $\begin{array}{c}1996 \\
n=4,370 \\
\end{array}$ & $\begin{array}{c}2000 \\
n=4,854\end{array}$ & $\begin{array}{c}1996 \\
n=4,370\end{array}$ & $\begin{array}{c}2000 \\
n=4,854\end{array}$ & $\begin{array}{c}1995 \\
n=3,818 \\
\end{array}$ & $\begin{array}{c}2000 \\
n=3,040\end{array}$ & $\begin{array}{c}1995 \\
n=3,818 \\
\end{array}$ & $\begin{array}{c}2000 \\
n=3,040\end{array}$ \\
\hline \multicolumn{9}{|l|}{ Demographic } \\
\hline \multicolumn{9}{|l|}{ Age, years } \\
\hline $50-54$ & 74 & 74 & 72 & 79 & - & - & - & - \\
\hline $55-59$ & 69 & 73 & 72 & 76 & - & - & - & - \\
\hline $60-64$ & 63 & 70 & 71 & 78 & - & - & - & - \\
\hline $70-74$ & - & - & - & - & 54 & 57 & 65 & 77 \\
\hline $75-79$ & - & - & - & - & 44 & 47 & 59 & 65 \\
\hline $80-84$ & - & - & - & - & 31 & 36 & 43 & 54 \\
\hline $85-89$ & - & - & - & - & 23 & 25 & 37 & 42 \\
\hline White & 68 & 70 & 72 & 77 & 42 & 43 & 54 & 62 \\
\hline Black & 68 & 70 & 73 & 78 & 47 & 44 & 57 & 58 \\
\hline \multicolumn{9}{|l|}{ Socioeconomic } \\
\hline Completed high school & 71 & 72 & 76 & 80 & 46 & 48 & 61 & 68 \\
\hline Not completed high school & 57 & 60 & 60 & 69 & 35 & 35 & 44 & 49 \\
\hline Born in the United States & 68 & 70 & 72 & 77 & 42 & 44 & 54 & 62 \\
\hline Born abroad & 70 & 68 & 71 & 77 & 38 & 43 & 50 & 61 \\
\hline Married & 71 & 73 & 75 & 81 & 49 & 52 & 64 & 71 \\
\hline Not married & 61 & 63 & 64 & 70 & 38 & 38 & 48 & 56 \\
\hline \multicolumn{9}{|l|}{ Income category* } \\
\hline 1 & 58 & 65 & 59 & 73 & 35 & 34 & 44 & 49 \\
\hline 2 & 65 & 64 & 69 & 73 & 42 & 41 & 54 & 58 \\
\hline 3 & 70 & 69 & 76 & 77 & 44 & 47 & 58 & 67 \\
\hline 4 & 80 & 80 & 85 & 87 & 50 & 51 & 63 & 71 \\
\hline \multicolumn{9}{|l|}{ Health } \\
\hline Smokers & 57 & 58 & 60 & 64 & 41 & 36 & 51 & 52 \\
\hline Non smokers & 71 & 72 & 75 & 81 & 42 & 44 & 54 & 62 \\
\hline Less physical activity & - & 66 & - & 75 & - & 40 & - & 58 \\
\hline Vigorous exercise & - & 74 & - & 80 & - & 52 & - & 70 \\
\hline Health excellent, very good, good & 70 & 72 & 73 & 79 & 45 & 46 & 56 & 64 \\
\hline Health poor or fair & 60 & 63 & 66 & 72 & 36 & 38 & 50 & 57 \\
\hline Cognitively normal & - & - & - & - & 44 & 44 & 57 & 64 \\
\hline Cognitively impaired & - & - & - & - & 34 & 40 & 40 & 48 \\
\hline \multicolumn{9}{|l|}{ Subjective life expectation ${ }^{\dagger}$} \\
\hline $0 \%-33 \%$ & 61 & 64 & 65 & 73 & 37 & 36 & 48 & 54 \\
\hline $34 \%-66 \%$ & 64 & 69 & 70 & 77 & 48 & 49 & 63 & 68 \\
\hline $67 \%-100 \%$ & 73 & 74 & 75 & 81 & 49 & 50 & 60 & 67 \\
\hline \multicolumn{9}{|l|}{ Health care } \\
\hline Uninsured & 46 & 49 & 44 & 52 & - & - & - & - \\
\hline Insured & 71 & 71 & 75 & 80 & - & - & - & - \\
\hline No additional private insurance & - & - & - & - & 37 & 43 & 45 & 62 \\
\hline Additional private insurance & - & - & - & - & 43 & 61 & 57 & 74 \\
\hline Not in hospital last year & 68 & 70 & 71 & 77 & 43 & 44 & 54 & 62 \\
\hline Hospitalized in the last year & 64 & 66 & 73 & 78 & 39 & 42 & 53 & 61 \\
\hline 0-2 physician visits last year & 59 & 57 & 59 & 63 & 41 & 33 & 50 & 47 \\
\hline 3-5 physician visits last year & 73 & 75 & 78 & 82 & 44 & 44 & 56 & 62 \\
\hline $6+$ physician visits last year & 72 & 74 & 78 & 82 & 42 & 46 & 57 & 66 \\
\hline $\begin{array}{l}\text { Pap }=\text { Papanicolaou; HRS }=\text { Health and } \\
* \text { Income categories: HRS }-1996: 1, \leq \$ \\
4,>\$ 49,504 \text {. AHEAD }-1995: 1, \leq \$ 10 \\
4,>\$ 18,840 \text {. } \\
\text { † Subjective life expectation: HRS: "(Wha } \\
\text { chances that you will live another } 5 \text { year }\end{array}$ & $\begin{array}{l}\text { Retirement Stu } \\
3,000 ; 2, \$ 13 \text {, } \\
560 ; 2, \$ 10,56 \\
\text { is the percent } \\
\text { "u }\end{array}$ & $\begin{array}{l}y ; A H E A D=A \\
01-\$ 31,600 ; 3 \\
-\$ 18,000 ; 3, \$ \\
\text { nance) that you }\end{array}$ & $\begin{array}{l}\text { te and Health D } \\
31,601-\$ 58,26 \\
3,001-\$ 30,000 \text {; } \\
\text { ill live to be } 75\end{array}$ & $\begin{array}{l}\text { ynamics Among } \\
; 4,>\$ 58,26 \\
4,>\$ 30,000 \text {. } \\
\text { or more?" AHE }\end{array}$ & $\begin{array}{l}\text { e Oldest Old. } \\
000: 1, \leq \$ 8 \text {, } \\
00,1, \leq \$ 8,4 \\
\text { : "Using a nu }\end{array}$ & $\begin{array}{l}295 ; 2, \$ 8,296- \\
0 ; 2, \$ 8,401-\$ \\
\text { nber from } 0 \text { to }\end{array}$ & $\begin{array}{l}0,420 ; 3, \$ 20, \\
000 ; 3, \$ 12,00 \\
0) \text { what do you }\end{array}$ & $\begin{array}{l}21-\$ 49,504 ; \\
1-\$ 18,840 ; \\
\text { think are the }\end{array}$ \\
\hline
\end{tabular}


Those who thought there was a better chance that they would live beyond the age of 75 years were more likely to be screened than those who did not. Lacking supplemental health insurance was related to lower rates of screening. Hospitalization in the last year had little effect, whereas those with more outpatient visits in the last year were more likely to be screened.

In bivariate analyses of AHEAD (Table 1) data, differences between blacks and whites were also small. Consistent with the findings from HRS, higher education, being married, higher income, not smoking, no cognitive impairment, perception of health to be excellent, very good, or good, and higher subjective life expectation were positively related to both screening behaviors. Elderly persons with additional health insurance were more likely to be screened than their counterparts without additional health insurance. Hospitalization in the last year did not affect outcomes, but

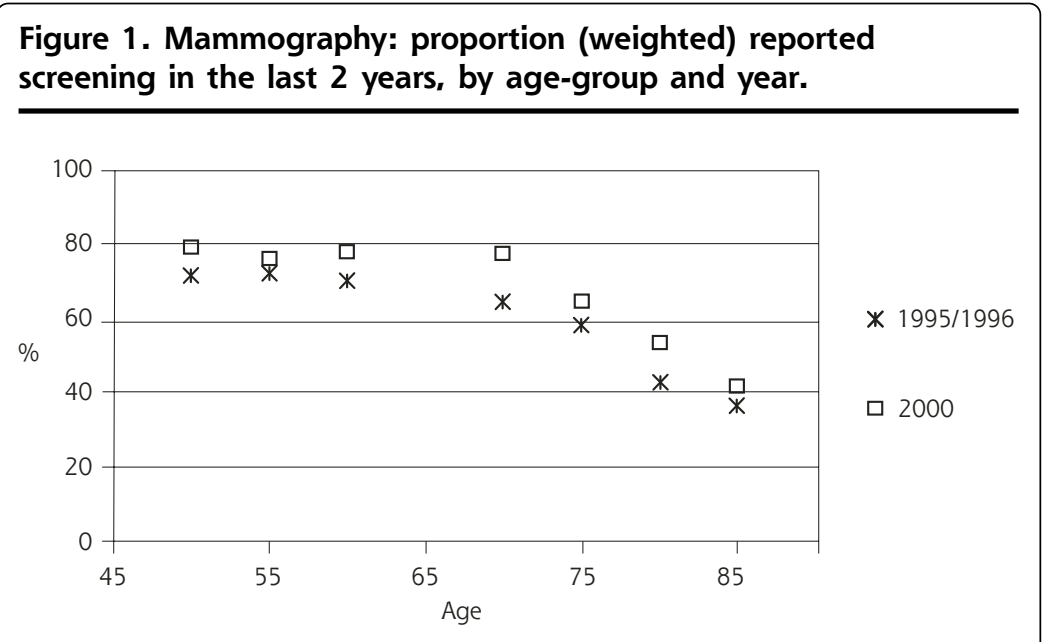

Figure 2. Cervical cancer: proportion (weighted) reported screening in the last 2 years, by age-group and year.

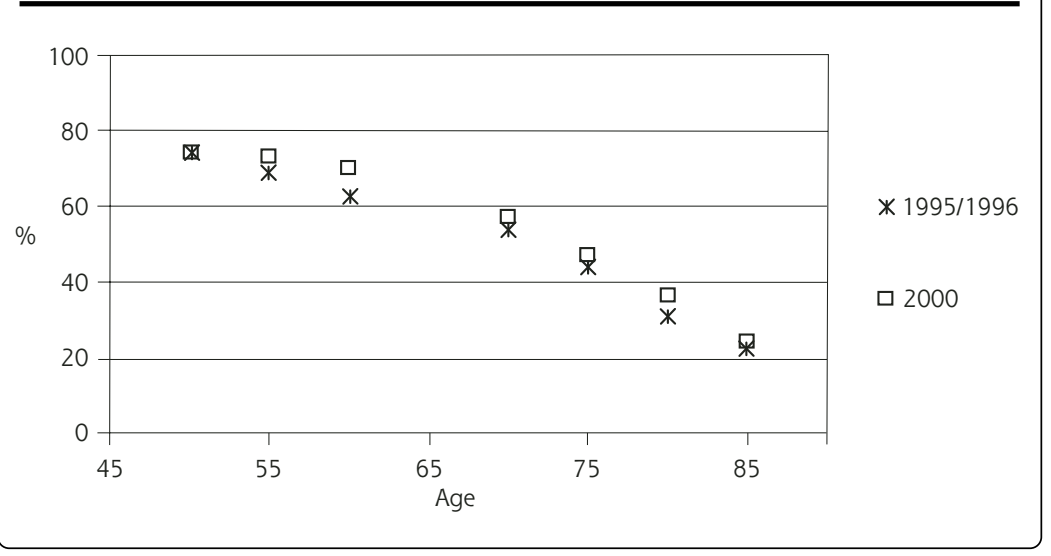

those who had more physician visits were more likely to be screened.

The multivariate results (HRS, Table 2; AHEAD, Table 3 ) are broadly consistent with the bivariate results. In HRS, there were significant increases in mammography screening from 1995/1996 to 2000 . Because of the large number of independent variables tested in the models, which therefore increased the probability of type I error, the significance of $95 \%$ confidence intervals around the odds ratios with upper or lower bounds close to 1 must be interpreted with caution.

For mammography screening, there was no decline by age in HRS, but a decline by age was observed in AHEAD. There was a decline in Pap tests by agegroup in both surveys. Higher education, being married, higher income, not smoking and vigorous exercise were significantly associated with higher screening rates in all models. Black women were more likely to report having been screened in the last 2 years than white women. In HRS those with health insurance and in AHEAD those with additional health insurance were more likely to have received screening. More physician visits also remained significantly associated with screening in all models.

In HRS those with the highest subjective life expectation were more likely to have received either screening test. In AHEAD those with subjective life expectation in the middle range (34\% to $66 \%$ ) were more likely to have received a mammogram than those with lower or higher subjective survival expectations; screening rates for those most optimistic regarding their future survival did not differ significantly from the most pessimistic group.

\section{DISCUSSION}

\section{Period Effects}

In bivariate analyses screening rates increased from the 1995/1996 wave to the 2000 wave in all age-groups and for both screening tests. These increases might be attributable to better access to health services in general, increases in the perception 
of the utility of these interventions, or increasing concern regarding the diseases in question. The increases for mammography screening remained significant in the HRS models after adjusting for covariates.

\section{Age Effects}

Our data show a consistent age-related pattern of decline for both screening tests in both surveys and for both question periods. This decline might be explained by weak recommendations and little evidence of effect of screening in old women. Possible, but not mutually exclusive, explanations for lack of effect include increasing mortality from competing illnesses, diminishing importance of finding asymptomatic disease in participants with established illness, and reduced probability of living long enough to benefit from the discovery of asymptomatic cancer.

Table 2. Adjusted Relative Odds of Receipt of Cancer-Screening Services: Health and Retirement Study (HRS) Multivariate Models

\begin{tabular}{|c|c|c|}
\hline Variables & $\begin{array}{c}\text { Pap Test } \\
\text { Full Model } \\
\text { OR }(95 \% \mathrm{Cl}) \\
(\mathrm{n}=10,146) *\end{array}$ & $\begin{array}{c}\text { Mammogram } \\
\text { Full Model } \\
\text { OR }(95 \% \mathrm{Cl}) \\
(\mathrm{n}=10,156) *\end{array}$ \\
\hline \multicolumn{3}{|l|}{ Demographic ${ }^{\dagger}$} \\
\hline Year 2000 & $0.96(0.88-1.05)$ & $1.22(1.11-1.35)$ \\
\hline Age $55-59.9$ years & $0.97(0.87-1.08)$ & $1.17(1.04-1.31)$ \\
\hline Age $60-64.9$ years & $0.87(0.78-0.97)$ & $1.18(1.05-1.33)$ \\
\hline Black & $1.38(1.22-1.56)$ & $1.37(1.20-1.57)$ \\
\hline \multicolumn{3}{|l|}{ Socioeconomic $¥$} \\
\hline Completed high school & $1.25(1.13-1.40)$ & $1.26(1.12-1.41)$ \\
\hline Born in the United States & $0.86(0.74-1.00)$ & $0.80(0.68-0.94)$ \\
\hline Married & $1.22(1.10-1.35)$ & $1.30(1.17-1.45)$ \\
\hline Income category 1 & $0.63(0.55-0.73)$ & $0.55(0.47-0.65)$ \\
\hline Income category 2 & $0.60(0.52-0.68)$ & $0.58(0.50-0.67)$ \\
\hline Income category 3 & $0.69(0.60-0.79)$ & $0.64(0.55-0.74)$ \\
\hline \multicolumn{3}{|l|}{ Health $\S$} \\
\hline Smoking & $0.70(0.63-0.77)$ & $0.58(0.52-0.65)$ \\
\hline Vigorous exercise & $1.25(1.14-1.37)$ & $1.12(1.01-1.23)$ \\
\hline Poor or fair health & $0.77(0.69-0.87)$ & $0.80(0.70-0.91)$ \\
\hline Subjective life expectation $34 \%-66 \%$ & $1.03(0.91-1.16)$ & $1.03(0.90-1.17)$ \\
\hline Subjective life expectation $67 \%-100 \%$ & $1.28(1.14-1.44)$ & $1.15(1.01-1.23)$ \\
\hline \multicolumn{3}{|l|}{ Health carell } \\
\hline Uninsured & $0.53(0.46-0.61)$ & $0.38(0.34-0.44)$ \\
\hline In hospital in last year & $0.88(0.78-1.00)$ & $0.98(0.85-1.13)$ \\
\hline 3-5 physician visits in last year & $1.90(1.68-2.13)$ & $2.15(1.90-2.43)$ \\
\hline $6+$ physician visits in last year & $2.11(1.89-2.36)$ & $2.54(2.26-2.86)$ \\
\hline \multicolumn{3}{|c|}{$\begin{array}{l}\text { Pap = Papanicolaou; OR = odds ratio; } \mathrm{Cl}=\text { confidence interval. } \\
\text { * Number of observations in model. Most women contributed } 2 \text { observations: } 1996 \text { and } 2000 \text {. A total of } \\
5,942 \text { answered at least } 1 \text { survey question once. } \\
\text { † Reference categories: year }=1996 ; \text { age }=50-54.9 \text { years; race }=\text { white. } \\
\text { キ Reference categories: education }=\text { not completed high school; birth place }=\text { born abroad; marital status } \\
=\text { not married; income }=\text { category } 4 \text { (see footnote to Table } 1 \text { ). } \\
\S \text { Reference categories: smoking status }=\text { not smoking; exercise }=\text { less physical activity; health }=\text { excel- } \\
\text { lent, very good, or good; subjective life expectations }=0 \%-33 \% \text { (see footnote to Table } 1 \text { ). } \\
\text { II Reference categories: health insurance }=\text { some health insurance; hospitalization in last year }=\text { not in } \\
\text { hospital last year; physician visits in last year }=0-2 \text { visits in last year. }\end{array}$} \\
\hline
\end{tabular}

\section{Effect of Objective and Subjective Risk of Mortality on Screening}

The decision to obtain cancer screening is an individual one, made with varying amounts of information regarding risk of death by different persons. Our results suggest that both subjective and objective perceptions of mortality risk could play a role. In multivariate models older women with subjective views of their survival likelihood in the middle of the distribution (probability 0.34 to 0.66 ) were more likely to obtain screening compared with women with lower survival expectations. Reasons for avoiding screening by those in the distribution tails (very pessimistic, very optimistic) might be explained by opposite attitudes: in the first case the women might view such screening as hopeless, in the latter they might view it as unnecessary. The most interesting aspect of our findings with respect to risk perceptions is that survival expectations remain significant predictors even after controlling for many other plausible predictors of screening, suggesting that the women have inside information that is not readily obvious from commonly observed variables. The role of individual perceptions and beliefs about risk warrants more investigation in the study of the use of preventive services generally. It is not clear whether interventions that attempt to change such perceptions are feasible.

\section{Continued Screening in Old Age}

Physician actions contributing to screening could reflect a case-by-case basis for screening in these age-groups. Although there is a decline in rates with age, the continuing (and, from 1996 to 2000, apparently increasing) utilization of these screening tests in older age-groups might be excessive.

Based on population data from 1996 and $2000,{ }^{15,16}$ the proportion in each age-group reporting having received a screening test in the last 2 years in AHEAD (Table 1) and a cost per mammogram of $\$ 100$ and a cost of a Pap test of $\$ 14.60,{ }^{17}$ we estimate that approximately 3.7 million screening mammograms at a total cost of $\$ 370$ million and 2.8 million Pap tests at a total cost of $\$ 41$ million were performed in 1996 among women 70 years of age and older. In 2000 the 
Table 3. Adjusted Relative Odds of Receipt of Cancer Screening Services: Asset and Health Dynamics Among the Oldest Old (AHDEAD) Multivariate Models

\begin{tabular}{|c|c|c|}
\hline Variables & $\begin{array}{c}\text { Pap Test } \\
\text { Full Model } \\
\text { OR }(95 \% \mathrm{Cl}) \\
(\mathrm{n}=6,330)^{*}\end{array}$ & $\begin{array}{l}\text { Mammogram } \\
\text { Full Model } \\
\text { OR }(95 \% \mathrm{Cl}) \\
(\mathrm{n}=6,347)^{*}\end{array}$ \\
\hline \multicolumn{3}{|l|}{ Demographic ${ }^{\dagger}$} \\
\hline Year 2000 & $0.91(0.76-1.09)$ & $1.11(0.93-1.33)$ \\
\hline Age $75-79.9$ years & $0.84(0.74-0.96)$ & $0.93(0.81-1.06)$ \\
\hline Age $80-84.9$ years & $0.54(0.46-0.63)$ & $0.61(0.52-0.71)$ \\
\hline Age $85-89.9$ years & $0.41(0.33-0.51)$ & $0.46(0.37-0.56)$ \\
\hline Black & $1.58(1.34-1.87)$ & $1.57(1.40-1.78)$ \\
\hline \multicolumn{3}{|l|}{ Socioeconomic $¥$} \\
\hline Completed high school & $1.37(1.22-1.55)$ & $1.58(1.40-1.78)$ \\
\hline Born in the United States & $0.83(0.69-1.01)$ & $0.67(0.55-0.81)$ \\
\hline Married & $1.32(1.17-1.48)$ & $1.30(1.15-1.47)$ \\
\hline Income category 1 & $0.77(0.65-0.90)$ & $0.64(0.54-0.75)$ \\
\hline Income category 2 & $0.82(0.70-0.95)$ & $0.74(0.63-0.87)$ \\
\hline Income category 3 & $0.88(0.76-1.02)$ & $0.91(0.78-1.07)$ \\
\hline \multicolumn{3}{|l|}{ Health§ } \\
\hline Smoking & $0.77(0.64-0.94)$ & $0.74(0.61-0.90)$ \\
\hline Vigorous exercise & $1.36(1.21-1.53)$ & $1.32(1.16-1.49)$ \\
\hline Poor or fair health & $0.79(0.70-0.89)$ & $0.91(0.80-1.03)$ \\
\hline Cognitive impairment & $0.97(0.79-1.18)$ & $0.73(0.60-0.88)$ \\
\hline Subjective life expectation 34\%-66\% & $1.11(0.98-1.27)$ & $1.26(1.11-1.44)$ \\
\hline Subjective life expectation 67\%-100\% & $1.13(0.99-1.28)$ & $1.10(0.97-1.27)$ \\
\hline \multicolumn{3}{|l|}{ Health carell } \\
\hline Additional private insurance & $1.20(1.01-1.44)$ & $1.31(1.10-1.57)$ \\
\hline In hospital in last year & $1.00(0.88-1.14)$ & $0.97(0.85-1.10)$ \\
\hline 3-5 physician visits in the last year & $1.43(1.24-1.65)$ & $1.63(1.41-1.88)$ \\
\hline $6+$ physician visits in the last year & $1.61(1.39-1.85)$ & $2.01(1.74-2.32)$ \\
\hline \multicolumn{3}{|c|}{$\begin{array}{l}\text { Pap = Papanicolaou; OR = odds ratio; } \mathrm{Cl}=\text { confidence interval. } \\
\text { * Number of observations in model }- \text { most women contributed } 2 \text { observations: } 1995 \text { and } 2000 \text {. A total of } \\
4,543 \text { women answered at least } 1 \text { survey question once. } \\
\text { † Reference categories: year }=1995 ; \text { age }=70-74.9 \text { years; race }=\text { white. } \\
\text { † Reference categories: education }=\text { not completed high school; birth place = born abroad; marital status } \\
=\text { not married; income }=\text { category } 4 \text { (see footnote to Table } 1 \text { ). } \\
\text { § Reference categories: smoking status = not smoking; exercise }=\text { less physical activity; health }=\text { excel- } \\
\text { lent-very good-or good; mental status = cognitively normal; subjective life expectation }=0 \%-33 \% \text { (see } \\
\text { footnote to Table 1). } \\
\text { II Reference categories: health insurance }=\text { no other private insurance; hospitalization in last year = not in } \\
\text { hospital last year; physician visits in last year }=0-2 \text { physicians in last year. }\end{array}$} \\
\hline
\end{tabular}

age ${ }^{18}$ should argue for limited cervical screening among the elderly. The continued use might be because some authors still consider the tests useful for women in the oldest age-groups ${ }^{19-21}$ despite the lack of evidence from randomized controlled trials.

Walter and Covinsky ${ }^{22}$ have proposed a framework for when it might be reasonable to screen among the elderly. They suggest basing the screening decision on quantitative estimates of life expectancy, risk of cancer death, and screening outcomes based on published data. According to their framework, patients with a life expectancy of less than 5 years are not likely to have reduced mortality and therefore would not benefit from cancer screening. The potential for harm from a screening (which becomes greater as life expectancy decreases) is also taken into account. Walter and Covinsky recognize that many cancerscreening decisions for the elderly cannot be based on quantitative estimates of benefit and harm that might result from the screening. They therefore also recommend considering the predicted outcomes in accordance with the patient's own values and preferences for making informed screening decisions.

They estimate that as many as 240 very healthy 80 -year-old women need to be screened with mammography to prevent 1 death from breast cancer, and that this number goes up drastically as general life expectancy decreases. They also conclude that

numbers had increased to 4.6 million screening mammograms at a total cost of $\$ 460$ million and 3.7 million Pap tests at a total annual cost of $\$ 47$ million among women 70 years of age and older. These costs do not include subsequent follow-up costs for further evaluation and clinical management.

Although both mammography and Pap tests are covered by Medicare and are thus not paid for by the seniors themselves, the societal costs of continuing to perform these tests among the oldest old are substantial. This argument can be made even more strongly for Pap tests than for mammography. Although utilization rates do drop in the oldest age-groups, the low relative rates of mortality from cervical cancer in old elderly women who have had repeated normal Pap smear findings during their reproductive years do not benefit from continued Pap testing. This estimate is consistent with work based on decision modeling. ${ }^{23}$

\section{Other Factors Predicting Use of Screening}

In a study based on the Medicare Current Beneficiary Survey, $26.7 \%$ of women older than 75 years were found to have had a mammogram in the last 2 years. ${ }^{24}$ Mammography was related to functional status and inversely related to age. A smaller study from Connecticut ${ }^{25}$ concluded that screening mammography might be overused among elderly women, especially among those least likely to benefit, namely, those with 
a relatively poor general mortality prognosis.

It has been shown that those at higher risk for cancer are less likely to have access to screening than those who are at lower risk, ${ }^{26}$ and that persons with higher socioeconomic status are more likely to be screened than those with fewer resources. ${ }^{27-29}$ Access to health care, insurance, and engaging in other healthy behaviors appear to influence a woman's likelihood of obtaining a screening mammogram. ${ }^{30}$ Roberts and Birch ${ }^{31}$ found that factors affecting screening include insurance type, provider type, long waiting times, and poor communication among the physician, the staff, and the patient. In another mammography study, significant correlates of utilization included age, household income, and the type of managed care organization in which the member was enrolled. ${ }^{32}$ A study of preventive services and the elderly found that those who had no additional insurance coverage were approximately 10 percentage points less likely to receive influenza vaccination, cholesterol testing, mammography, or Pap smears than those who had such coverage. ${ }^{33}$

These earlier studies were mostly done among those who were young and middle-aged under the assumption that lower use of screening tests is detrimental. Although this assumption is not as valid in older women, our findings are consistent with these earlier studies. Women who smoke, who are less physically active, who deem their health to be poor or fair, or who have a low subjective life expectation are less likely to be screened. Women who have completed high school, are married, have a higher income, visit their physician more often, and have more health insurance are more likely to be screened. All these findings persist from middle (HRS) to old age (AHEAD). It is particularly noteworthy that the discrepancy for more screening among those with better resources outlasts the equalizing effect of Medicare coverage for these services after the age of 65 years. Generally, these findings are consistent in bivariate analyses and multivariate analyses and for both screening tests.

\section{Strengths and Limitations}

Strengths of the study include its large, prospective, representative, national sample of middle-aged and eld erly American women, and its inclusion of information on both cancer-screening utilization and predictors for utilization from more than one point in time for each individual.

A limitation is that the screening behavior is based on self-report. Although certain studies conclude that self-report of mammography is generally valid in population studies, ${ }^{34}$ other authors conclude that self-report might overestimate the receipt of mammography and Pap smears. ${ }^{35-37}$ Additionally, although the screening questions were part of the preventive services section of the questionnaires, some women might have reported receipt of a diagnostic (rather than a screening) mammogram. The wording of the questions might also be interpreted somewhat differently by different respondents. Because the wording in the questionnaires refers to the period "within the last two years," the proportions reporting having received the screening test, as reported in Table 1, are higher than annual rates. Because it is possible that women might have had 1 or more of each test in the last 2 years, we cannot simply halve the reported rates to calculate the annual rates; ie, the corresponding annual rates lie somewhere between our reported rates and one-half of these rates. Given the lack of detail provided from the surveys regarding women's history and treatment of breast cancer, we were unable to consider women with a history of breast cancer in a separate category for our analysis. Finally, many of the women in these age-groups might have had hysterectomies for benign indications; for elderly women without a uterus, the utility for getting regular Pap tests is likely even smaller than for those with a uterus. Unfortunately, data on whether the survey participants had had a hysterectomy were not collected.

\section{CONCLUSION}

Although the use of mammography and Pap tests for screening is lower among older than middle-aged women, elderly women are receiving a large and recently increasing number of screening mammograms and Pap tests. This continued widespread general screening, at substantial societal cost, takes place despite limited scientific evidence of advantage. We believe that information about these screening rates in older women, combined with education about the limited evidence of effect, should be provided to providers. Furthermore, screening among the elderly should be better and more specifically addressed in national clinical guidelines.

To read commentaries or to post a response to this article, see the online version at http://www.annfammed.org/cgi/content/full/1/4/209.

Key words: Aged; cohort studies; health services for the aged; mammography; Papanicolaou test; preventive health services

Submitted September 18, 2002; submitted, revised, January 6, 2003; accepted January 27, 2003.

Funding support: This work was supported by a grant from the National Institute on Aging (1RO1-AG-15868).

Acknowledgments: The authors would like to thank Lynn van Scoyoc for managing and analyzing the data. Thanks to Katrina Krause and Tara Hackney for editing the manuscript. 


\section{References}

1. Canadian Cancer Society. National Cancer Institute of Canada. Advisory Committee on Records and Registries. Canadian Cancer Statistics 1995. Toronto, Canada: Canadian Cancer Society; 1995

2. Otten JD, van Dijck JA, Peer PG, et al. Long term breast cancer screening in Nijmegen, The Netherlands: the nine rounds from 1975-92. J Epidemiol Community Health. 1996;50:353-358.

3. Tabar L, Fagerberg G, Chen HH, et al. Efficacy of breast cancer screening by age. New results from the Swedish Two-County Trial. Cancer. 1995;75:2507-2517.

4. US Preventive Services Task Force. Screening for breast cancer. Available at: http://www.ahcpr.gov/clinic/3rduspstf/breastcancer/. Accessed March 11, 2002

5. US Preventive Services Task Force. Guide to Clinical Preventive Services: Report of the U.S. Preventive Services Task Force. 2nd ed. Baltimore MD: Williams \& Wilkins; 1996

6. American Cancer Society. Early detection worksheet for women. Available at: http://www.cancer.org/downloads/PED/Prevention_and_ Early_Detection_for_Women_043001.pdf. Accessed January 2, 2003.

7. American College of Preventive Medicine. Clinical preventive services. Available at: http://www.acpm.org/clinical.htm\#Cervical Cancer. Accessed March 29, 2002.

8. Institute for Clinical Systems Improvement. Health care guideline: cervical cancer screening. Available at: http://www.icsi.org/display_ file. asp?Fileld $=145 \varepsilon$ title $=$ Cervical Cancer Screening. Accessed September 10, 2003

9. National Council for Quality Assurance. The state of health care quality. Available at: http://www.ncqa.org/sohc2002/. Accessed August 10, 2002.

10. US Dept of Health and Human Services. Healthy People 2010: Understanding and Improving Health. 2nd ed. Washington, DC: US Dept of Health and Human Services; 2000.

11. Juster FT, Suzman R. An overview of the Health and Retirement Study. J Hum Resour. 1995;30(suppl):S7-S56.

12. Myers GC, Juster FT, Suzman RM. Asset and Health Dynamics Among the Oldest Old (AHEAD): initial results from the longitudinal study. Introduction. J Gerontol B Psychol Sci Soc Sci. 1997;52:v-viii.

13. Huber PJ. The behavior of maximum likelihood estimates under non standard conditions. In: Proceedings of the Fifth Berkeley Symposium in Mathematical Statistics and Probability. Vol 1. Berkeley: University of California Press;1967:221-233.

14. White $\mathrm{H}$. A heteroskedasticity-consistent covariance matrix estimator and a direct test for heteroskedasticity. Econometrica. 1980;48:817838

15. US Census Bureau. Census 2000 data for the United States. Available at: http://www.census.gov/census2000/states/us.html. Accessed August 10, 2002.

16. US Census Bureau. Statistical abstract of the United States 1996. Available at: http://www.census.gov/prod/2/gen/96statab/pop.pdf. Accessed August 10, 2002.

17. National Cervical Cancer Coalition. Reimbursement issues. Available at: http://www.nccc-online.org. Accessed August 10, 2002.
18. Centers for Disease Control and Prevention Wonder database. Compressed mortality query. Available at: http://wonder.cdc.gov/mortsql. shtml. Accessed February 24, 2002.

19. Foley G. Challenging conventional wisdom in cancer care. Cancer Pract. 2001;9:113.

20. Johs-Artisensi J, McGill J. Screening mammography for elderly women. Cancer Pract. 2001;9:128-133.

21. Nattinger $A B$. Older women, mammography, and mortality from breast cancer. Am J Med. 2000;108:174-175.

22. Walter LC, Covinsky KE. Cancer screening in elderly patients: a framework for individualized decision making. JAMA. 2001;285: 2750-2756.

23. Cruickshank ME, Angus V, Kelly M, McPhee S, Kitchener HC. The case for stopping cervical screening at age 50. Br J Obstet Gynaecol. 1997; 104:586-589.

24. Blustein J, Weiss LJ. The use of mammography by women aged 75 and older: factors related to health, functioning, and age. J Am Geriatr Soc. 1998;46:941-946.

25. Scinto JD, Gill TM, Grady JN, Holmboe ES. Screening mammography: is it suitably targeted to older women who are most likely to benefit? J Am Geriatr Soc. 2001;49:1101-1104.

26. Kleinman JC, Kopstein A. Who is being screened for cervical cancer? Am J Public Health. 1981;71:73-76.

27. Juon HS, Choi Y, Kim MT. Cancer screening behaviors among Korean-American women. Cancer Detect Prev. 2000;24:589-601.

28. Facione NC. Breast cancer screening in relation to access to health services. Oncol Nurs Forum. 1999;26:689-696.

29. Caplan LS, Haynes SG. Breast cancer screening in older women. Public Health Rev. 1996:24:193-204.

30. Qureshi M, Thacker HL, Litaker DG, Kippes C. Differences in breast cancer screening rates: an issue of ethnicity or socioeconomics? J Womens Health Gend Based Med. 2000;9:1025-1031.

31. Roberts RA, Birch NJ. A comparison of breast cancer secondary prevention activities and satisfaction with access and communication issues in women 50 and over. Prev Med. 2001;32:348-358.

32. Barton MB, Moore S, Shtatland E, Bright R. The relation of household income to mammography utilization in a prepaid health care system. J Gen Intern Med. 2001;16:200-203.

33. Carrasquillo O, Lantigua RA, Shea S. Preventive services among Medicare beneficiaries with supplemental coverage versus HMO enrollees, medicaid recipients, and elders with no additional coverage. Med Care. 2001;39:616-626.

34. Zapka JG, Bigelow C, Hurley T, et al. Mammography use among sociodemographically diverse women: the accuracy of self-report. Am J Public Health. 1996;86:1016-1021.

35. Newell S, Girgis A, Sanson-Fisher R, Ireland M. Accuracy of patients' recall of Pap and cholesterol screening. Am J Public Health. 2000;90: 1431-1435

36. Bowman JA, Sanson-Fisher R, Redman S. The accuracy of self-reported Pap smear utilisation. Soc Sci Med. 1997;44:969-976.

37. McKenna MT, Speers M, Mallin K, Warnecke R. Agreement between patient self-reports and medical records for Pap smear histories. Am J Prev Med. 1992;8:287-291. 